\title{
Prognostic value of fibrinogen to albumin ratios among critically ill patients with acute kidney injury
}

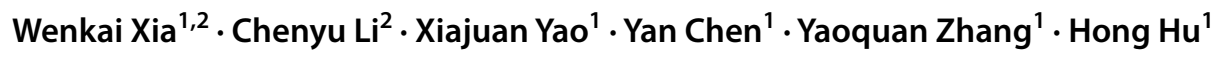

Received: 29 June 2021 / Accepted: 17 November 2021 / Published online: 30 November 2021

(c) The Author(s) 2021

\begin{abstract}
Fibrinogen to albumin ratios (FAR) have shown to be a promising prognostic factor for improving the predictive accuracy in various diseases. This study explores FAR's prognostic significance in critically ill patients with acute kidney injury (AKI). All clinical data were extracted from the Multiparameter Intelligent Monitoring in Intensive Care Database III version 1.4. All patients were divided into four groups based on FAR quartiles. The primary endpoint was in-hospital mortality. A generalized additive model was applied to explore a nonlinear association between FAR and in-hospital mortality. The Cox proportional hazards models were used to determine the association between FAR and in-hospital mortality. A total of 5001 eligible subjects were enrolled. Multivariate analysis demonstrated that higher FAR was an independent predictor of in-hospital mortality after adjusting for potential confounders (HR, 95\% CI 1.23, 1.03-1.48, $P=0.025$ ). A nonlinear relationship between FAR and in-hospital mortality was observed. FAR may serve as a potential prognostic biomarker in critically patients with AKI and higher FAR was associated with increased risk of in-hospital mortality among these patients.
\end{abstract}

Keywords Fibrinogen $\cdot$ Albumin $\cdot$ Acute kidney injury $\cdot$ Prognosis

\section{Introduction}

Acute kidney injury (AKI) is a prevalent complication in critically ill patients, which results in long length of intensive care unit (ICU) stay, increased morbidity and mortality, and high risk of chronic kidney disease (CKD) and endstage renal disease (ESRD) [1,2]. Emerging evidence has demonstrated that early screening and managing the risk factors associated with AKI prevent in-hospital mortality of critical patients $[3,4]$. Therefore, it is necessary to identify economic and reliable clinical indicators that can outperform or add significant value to the existing conventional score system for ICU patients with AKI.

Wenkai Xia and Chenyu Li have contribute equally to this manuscript.

Hong $\mathrm{Hu}$

huhong1523@163.com

1 Department of Nephrology, The Affiliated Jiangyin Hospital of Southeast University Medical College, 3 Yinrui Road, Jiangsu 214400, Jiangyin, China

2 Nephrologisches Zentrum, Medizinische Klinik und Poliklinik IV, Klinikum der Universität München, Ludwig-Maximilians-University Munich, Munich, Germany
The mechanisms underlying AKI are complicated and multifactorial, it is well recognized that inflammation is involved in the initiation and progression of AKI [5, 6]. Recent studies suggested that systemic inflammatory biomarkers can be utilized as potential predictors for AKI patients [7-9]. As a novel inflammation-based indicator, fibrinogen to albumin ratio (FAR) has gained prognostic value in various cancers [10-12] and myocardial infarction [13]. Additionally, several studies recently reported that FAR levels are associated with contrast-induced nephropathy and the occurrence of post-contrast acute kidney injury [14, 15]. However, data on the association of the FAR with prognosis of AKI patients are limited. The purpose of this study is to investigate the prognostic value of FAR in predicting inhospital mortality in critically ill patients with AKI.

\section{Methods}

\section{Data source}

Our study was based on a publicly available Multiparameter Intelligent Monitoring in Intensive Care III version 1.4 (MIMIC-III v1.4). The database includes more than 40,000 
critically ill patients admitted to Beth Israel Deaconess Medical Center (Boston, MA, USA) from 2001 to 2012 [16]. Access to the database for research was approved by the Institutional Review Boards of the Massachusetts Institute of Technology (Cambridge, MA, USA) and the Beth Israel Deaconess Medical Center. Given that all data were deidentified, informed consent was waived by the ethical committee of the Beth Israel Deaconess Medical Center. All methods were performed in accordance with the relevant guidelines and regulations.

\section{Population selection criteria}

According to the Kidney Disease Improving Global Outcomes (KDIGO) classification, adult patients ( $\geq 18$ years) with AKI who had been hospitalized in the ICU at first admission for more than 2 days were included. Patients who met the following criteria were excluded: (1) no albumin or fibrinogen measured during the ICU stay; (2) missing $>5 \%$ individual data.

\section{Data extraction}

Structured query language (SQL) with PostgreSQL (version 9.6) was used to perform data extraction from MIMIC-III. The comorbidities included atrial fibrillation (AFIB), coronary artery disease (CAD), congestive heart failure (CHF), renal disease, chronic liver diseases, diabetes, chronic obstructive pulmonary disease (COPD), pneumonia, acute respiratory distress syndrome (ARDS) and stroke. The laboratory parameters were also extracted, including white blood cell (WBC), hematocrit, hemoglobin, platelet, anion gap (AG), prothrombin time (PT), activated partial thromboplastin time (APTT), albumin, fibrinogen, blood urea nitrogen (BUN), creatinine, glucose, bicarbonate, chloride, sodium, potassium and total bilirubin. The FAR was defined as the ratio of the fibrinogen level to the albumin level. Furthermore, Sequential Organ Failure Assessment (SOFA) scores and Simplified Acute Physiology Score (SAPS) II were calculated as described in previous studies $[17,18]$. Only the data for the patient's first ICU admission was used for assessment and baseline data was extracted within $24 \mathrm{~h}$ after ICU admission. The primary endpoint was hospital mortality.

\section{Statistical analysis}

Baseline characteristics of all patients were stratified by FAR quartiles. Continuous variables were presented as mean \pm standard deviation $(\mathrm{SD})$ and categorical data were expressed as number or percentage. Chi-square, one-way ANOVA or Kruskal-Wallis tests were used to determine the significance difference between groups. The Cox proportional hazards models were constructed to examine the relationship between FAR levels and in-hospital mortality, and results were presented as hazard ratios (HRs) with 95\% confidence intervals (CIs). We also used a generalized additive model (GAM) to identify the nonlinear association between FAR and in-hospital mortality. Three multivariate models were constructed on the basis of FAR group inclusion according to quartiles. The second quartile was treated as the reference group. Subgroup analysis was performed to evaluate the association between FAR and in-hospital mortality, including age, gender, laboratory parameters, comorbidities, SOFA and SAPS II score. Receiver-operating characteristic (ROC) curve was applied to evaluate predictive ability of FAR and existing scoring system (SOFA score and SAPS II score) on in-hospital mortality. All statistical analyses were performed using SPSS 20.0 software (SPSS Inc., IBM, USA) and R software version 3.4.2 (Institute for Statistics and Mathematics, Vienna, Austria). A two-tailed value $<0.05$ was considered statistically significant.

\section{Results}

\section{Subject characteristics}

A total of 5001 eligible subjects were enrolled in our study. Characteristics of these patients by quartiles of FAR were summarized in Table 1. There were 2066 women and 2935 men with a mean age of $63 \pm 16$ years. Patients in top quartile of FAR were more likely to be elderly with a history of AFIB, CHF, renal disease, pneumonia, ARDS, malignancy and diabetes, as well as higher values of $\mathrm{WBC}$, creatine, BUN, anion gab, platelet, SOFA score, SAPSII score, ICU LOS, and mortality.

\section{FAR level and in-hospital mortality}

The relationship between FAR level and in-hospital mortality was non-liner, and a U-shaped curve was observed (Fig. 1). We used multivariate Cox regression analysis to determine the association between FAR and in-hospital mortality in critically ill patients with AKI (Table 2). Following the stratification of FAR into quartiles and using the second quartile as reference group. In model I, the top quartile of FAR (FAR $\geq 0.157)$ was associated with increased risk of in-hospital mortality after adjustment for age, gender and ethnicity (HR, 95\% CI 1.57, 1.33-1.84). In model II, after adjustment for age, gender, ethnicity, vasopressin use, ventilator use, atrial fibrillation, coronary artery disease, congestive heart failure, chronic liver disease, chronic kidney disease, stroke, malignancy, pneumonia, ARDS, and COPD, FAR was also an independent predictor of inhospital mortality (HR, 95\% CI 1.20, 1.01-1.42). In model 
Table 1 Baseline characteristics of participants according to FAR

\begin{tabular}{|c|c|c|c|c|c|}
\hline \multirow[t]{2}{*}{ Characteristics } & \multicolumn{4}{|l|}{ FAR } & \multirow[t]{2}{*}{$P$ value } \\
\hline & $\mathrm{Q} 1(<0.059)$ & Q2(0.059-<0.093) & Q3(0.093-<0.157) & $\mathrm{Q} 4(\geq 0.157)$ & \\
\hline Ages, years & $60 \pm 17$ & $63 \pm 16$ & $65 \pm 16$ & $64 \pm 16$ & $<0.001$ \\
\hline Gender, $n(\%)$ & & & & & $<0.001$ \\
\hline Female & 451 (36.6) & $469(37.7)$ & $556(43.7)$ & $590(47.2)$ & \\
\hline Male & $782(63.4)$ & $776(62.3)$ & $717(56.3)$ & $660(52.8)$ & \\
\hline Ethnicity, $n(\%)$ & & & & & $<0.001$ \\
\hline White & 878 (71.2) & $886(71.2)$ & $897(70.5)$ & $901(72.1)$ & \\
\hline Black & $72(5.8)$ & $78(6.3)$ & $119(9.3)$ & $116(9.3)$ & \\
\hline Other & $283(23)$ & $281(22.5)$ & $257(20.2)$ & 233 (18.6) & \\
\hline ICU LOS, day & $7.6 \pm 8.2$ & $7.3 \pm 8.0$ & $8.0 \pm 8.9$ & $9.5 \pm 10.0$ & $<0.001$ \\
\hline Vasopressin use, $n(\%)$ & $301(24.4)$ & $261(21.0)$ & $264(20.7)$ & $266(21.3)$ & 0.091 \\
\hline Ventilator use, $n(\%)$ & $502(40.7)$ & $439(35.3)$ & $378(29.7)$ & $330(26.4)$ & $<0.001$ \\
\hline \multicolumn{6}{|l|}{ Comorbidities, $n(\%)$} \\
\hline Atrial fibrillation & 365 (29.6) & $366(29.4)$ & $395(31.0)$ & $438(35.0)$ & 0.008 \\
\hline Coronary artery disease & $392(31.8)$ & $341(27.4)$ & $266(20.9)$ & $202(16.2)$ & $<0.001$ \\
\hline Congestive heart failure & $282(22.9)$ & $362(29.1)$ & $444(34.9)$ & $441(35.3)$ & $<0.001$ \\
\hline Chronic liver disease & $316(25.6)$ & $259(20.8)$ & $146(11.5)$ & $69(5.5)$ & $<0.001$ \\
\hline Renal disease & $148(12)$ & $167(13.4)$ & $229(18.0)$ & $233(18.6)$ & $<0.001$ \\
\hline Pneumonia & $283(23.0)$ & $337(27.1)$ & $427(33.5)$ & $468(37.4)$ & $<0.001$ \\
\hline COPD & $9(0.7)$ & $20(1.6)$ & $18(1.4)$ & $13(1.0)$ & 0.187 \\
\hline ARDS & $308(25.0)$ & $366(29.4)$ & $499(39.2)$ & $613(49.0)$ & $<0.001$ \\
\hline Stroke & $40(3.2)$ & $61(4.9)$ & $70(5.5)$ & $41(3.3)$ & 0.007 \\
\hline Cancer & $153(12.4)$ & $215(17.3)$ & $287(22.5)$ & $322(25.8)$ & $<0.001$ \\
\hline Diabetes uncomplicated & $272(22.1)$ & $332(26.7)$ & $365(28.7)$ & $368(29.4)$ & $<0.001$ \\
\hline \multicolumn{6}{|l|}{ Laboratory parameters } \\
\hline WBC, $10^{9} / \mathrm{L}$ & $12.1 \pm 12.4$ & $12.8 \pm 11.6$ & $13.7 \pm 14.5$ & $14.8 \pm 10.7$ & $<0.001$ \\
\hline Creatine, $\mathrm{mEq} / \mathrm{L}$ & $1.4 \pm 1.3$ & $1.5 \pm 1.4$ & $1.9 \pm 2.0$ & $2.1 \pm 2.1$ & $<0.001$ \\
\hline BUN, mg/dL & $25.9 \pm 20.5$ & $28.5 \pm 22.3$ & $33.7 \pm 25.9$ & $39.3 \pm 28.5$ & $<0.001$ \\
\hline Anion gap, mmol/L & $15.2 \pm 5.0$ & $15.6 \pm 5.2$ & $15.8 \pm 4.8$ & $16.1 \pm 5.1$ & $<0.001$ \\
\hline Bicarbonate, $\mathrm{mg} / \mathrm{dL}$ & $22.0 \pm 4.8$ & $22.3 \pm 4.9$ & $22.1 \pm 5.3$ & $21.5 \pm 5.6$ & 0.001 \\
\hline Bilirubin, $\mathrm{mg} / \mathrm{dL}$ & $3.9 \pm 7.8$ & $2.8 \pm 5.7$ & $2.0 \pm 4.4$ & $2.0 \pm 3.9$ & $<0.001$ \\
\hline Glucose, $\mathrm{mg} / \mathrm{dL}$ & $145.2 \pm 70.0$ & $153.7 \pm 82.6$ & $155.4 \pm 83.5$ & $150.9 \pm 87.6$ & 0.010 \\
\hline Hematocrit, $\%$ & $30.5 \pm 7.0$ & $31.9 \pm 7.0$ & $32.0 \pm 6.7$ & $31.0 \pm 6.3$ & $<0.001$ \\
\hline Sodium, mmol/L & $138.5 \pm 5.2$ & $138.4 \pm 7.6$ & $138.5 \pm 5.5$ & $138.1 \pm 5.9$ & 0.248 \\
\hline Potassium, mmol/L & $4.2 \pm 0.7$ & $4.2 \pm 0.8$ & $4.2 \pm 0.9$ & $4.2 \pm 0.9$ & 0.844 \\
\hline Platelet, $10^{9} / \mathrm{L}$ & $151.1 \pm 95.3$ & $180.0 \pm 107.5$ & $206.0 \pm 128.6$ & $241.3 \pm 161.5$ & $<0.001$ \\
\hline Chloride, $\mathrm{mmol} / \mathrm{L}$ & $106.0 \pm 6.8$ & $105.4 \pm 6.8$ & $105.0 \pm 6.9$ & $104.8 \pm 7.2$ & $<0.001$ \\
\hline Hemoglobin, $g / d L$ & $10.5 \pm 2.5$ & $10.9 \pm 2.4$ & $10.7 \pm 2.3$ & $10.3 \pm 2.1$ & $<0.001$ \\
\hline PT, seconds & $19.2 \pm 10.9$ & $17.3 \pm 8.3$ & $17.7 \pm 11.2$ & $18.5 \pm 12.8$ & $<0.001$ \\
\hline APTT, seconds & $48.7 \pm 28.7$ & $42.4 \pm 25.7$ & $39.9 \pm 23.2$ & $40.6 \pm 24.5$ & $<0.001$ \\
\hline \multicolumn{6}{|l|}{ Scoring systems } \\
\hline SOFA & $7.1 \pm 3.9$ & $6.5 \pm 3.8$ & $6.6 \pm 3.7$ & $7.1 \pm 4.0$ & $<0.001$ \\
\hline SAPSII & $41.3 \pm 14.9$ & $41.4 \pm 14.5$ & $44.5 \pm 15.2$ & $46.7 \pm 15.6$ & $<0.001$ \\
\hline AKI stage, $n(\%)$ & & & & & $<0.001$ \\
\hline Stage 1 & $78(6.3)$ & $88(7.1)$ & $149(11.7)$ & $170(13.6)$ & \\
\hline Stage 2 & $260(21.1)$ & $277(22.2)$ & $309(24.3)$ & $404(32.3)$ & \\
\hline Stage 3 & 895 (72.6) & $880(70.7)$ & $815(64.0)$ & $676(54.1)$ & \\
\hline RRT, $n(\%)$ & $54(4.4)$ & $82(6.6)$ & $101(7.9)$ & $60(4.8)$ & $<0.001$ \\
\hline In hospital mortality, $n(\%)$ & $256(20.8)$ & $257(20.6)$ & $369(29.0)$ & $389(31.1)$ & $<0.001$ \\
\hline
\end{tabular}

$A R D S$ acute respiratory distress syndrome; $C O P D$ Chronic obstructive pulmonary disease; $B U N$ blood urea nitrogen; $W B C$ white blood cell; $P T$ prothrombin time; APTT activated partial thromboplastin time; SOFA sequential organ failure assessment; SAPSII simplified acute physiology score II; $A K I$ acute kidney injury; ICU intensive care unit; LOS length of stay; RRT renal replacement therapy 


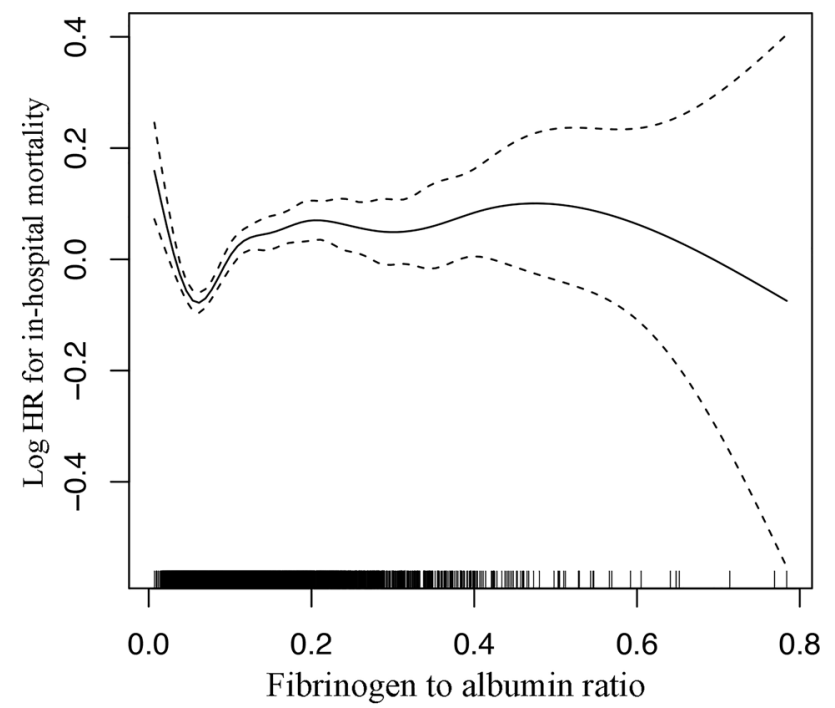

Fig. 1 Association between FAR and in-hospital mortality. A threshold, nonlinear association between FAR and in-hospital mortality was observed in a generalized additive model

III, after adjustment for more confounding factors, higher FAR remained a significant predictor of in-hospital mortality in critically ill patients with AKI (HR, 95\% CI 1.48, 1.04-2.10).

\section{Subgroup analysis}

We performed subgroup analysis to assess the association between FAR and in-hospital mortality (Table 3 ). There was no statistically significant in several strata $(P$ for interaction $>0.05)$. We found that patients with higher FAR had significantly higher mortality with SOFA score $<5$ and SAPSII score $<39$. Similar trends were observed in patients with congestive heart failure, coronary artery disease, atrial fibrillation, pneumonia and cancer.

\section{Prediction of mortality}

The ROC curves were generated using the indicated variables (Fig. 2). The AUC for SOFA score was 0.690, compared to 0.700 for FAR plus SOFA score $(P<0.001)$. Moreover, the AUCs for SAPSII score and FAR plus SAPSII score were 0.734 and 0.736 , respectively $(P<0.001)$.

\section{Discussion}

In our study, we observed an elevated FAR level was associated with increased risk of in-hospital mortality after adjusting for important confounding factors, and the relationship between FAR and mortality was nonlinear. To the best of our knowledge, this is the first study to measure the association between FAR and in-hospital mortality in critically ill patients with AKI.

The FAR is a combination of fibrinogen and albumin level that serves as a potential prognostic biomarker to predict risk for various diseases. Zou et al. reported the association between the FAR level and mortality in peritoneal dialysis (PD) patients, and they found that FAR was an independent predictor of both all-cause and cardiovascular disease (CVD) mortality [19]. Liu et al. suggested that a high FAR strongly correlated with worse overall survival in renal cancer patients [20]. Another retrospective study explored a significant association between higher FAR and occurrence of AKI in patients undergoing percutaneous coronary intervention [15].

Currently, fibrinogen has been shown to go beyond its traditional role in coagulation and to recognized as an acutephase response protein [21]. It has been proposed that FAR
Table 2 Relationship between quartile of FAR and in-hospital mortality

\begin{tabular}{|c|c|c|c|c|c|c|}
\hline & \multicolumn{2}{|c|}{ Quartile1 $(N=1233)$} & \multicolumn{2}{|c|}{ Quartile3 $(N=1273)$} & \multicolumn{2}{|c|}{ Quartile4 $(N=1250)$} \\
\hline & HR $(95 \% \mathrm{CI})$ & $P$ value & HR $(95 \% \mathrm{CI})$ & $P$ value & HR $(95 \% \mathrm{CI})$ & $P$ value \\
\hline Unadjusted & $1.02(0.85,1.21)$ & 0.841 & $1.36(1.16,1.59)$ & $<0.001$ & $1.54(1.32,1.81)$ & $<0.001$ \\
\hline Model I & $1.02(0.86,1.21)$ & 0.813 & $1.37(1.17,1.61)$ & $<0.001$ & $1.57(1.33,1.84)$ & $<0.001$ \\
\hline Model II & $0.91(0.77,1.09)$ & 0.308 & $1.10(0.93,1.30)$ & 0.250 & $1.20(1.01,1.42)$ & 0.037 \\
\hline Model III & $1.04(0.86,1.27)$ & 0.692 & $1.24(0.98,1.56)$ & 0.068 & $1.48(1.04,2.10)$ & 0.028 \\
\hline
\end{tabular}

Reference group was Quartile 2

$H R$ hazard ratio

Model I: adjusted for age, gender and ethnicity

Model II: adjusted for model I covariates and vasopressin use, ventilator use, atrial fibrillation, coronary artery disease, congestive heart failure, chronic liver disease, renal disease, stroke, cancer, pneumonia, acute respiratory distress syndrome, chronic obstructive pulmonary disease and RRT

Model III: adjusted for model II covariates and hemoglobin, WBC, creatine, BUN, anion gap, bicarbonate, bilirubin, glucose, hematocrit, sodium, potassium, platelet, chloride, hemoglobin, PT, APTT, AKI stage 
Table 3 Subgroup analysis of the association between FAR and inhospital mortality

\begin{tabular}{|c|c|c|c|c|}
\hline Characteristic & $N$ & $\mathrm{HR}(95 \% \mathrm{CI})$ & $P$ value & $P$ for interaction \\
\hline Age & & & & 0.227 \\
\hline$<65$ & 2571 & $1.64(1.32,2.04)$ & $<0.001$ & \\
\hline$\geq 65$ & 2430 & $1.82(1.45,2.29)$ & $<0.001$ & \\
\hline Gender & & & & 0.506 \\
\hline Female & 2066 & $1.52(1.19,1.94)$ & 0.001 & \\
\hline Male & 2935 & $1.86(1.51,2.29)$ & $<0.001$ & \\
\hline Vasopressin use & & & & $<0.001$ \\
\hline No & 3909 & $1.11(0.90,1.38)$ & 0.327 & \\
\hline Yes & 1092 & $1.63(1.23,2.17)$ & 0.001 & \\
\hline Ventilator use & & & & 0.403 \\
\hline No & 3352 & $1.50(1.24,1.81)$ & $<0.001$ & \\
\hline Yes & 1649 & $1.51(1.15,1.97)$ & 0.003 & \\
\hline AFIB & & & & 0.009 \\
\hline No & 3437 & $1.25(1.03,1.51)$ & 0.025 & \\
\hline Yes & 1564 & $1.58(1.11,2.24)$ & 0.010 & \\
\hline CAD & & & & $<0.001$ \\
\hline No & 3800 & $1.27(1.07,1.50)$ & 0.005 & \\
\hline Yes & 1201 & $6.01(3.70,9.74)$ & $<0.001$ & \\
\hline $\mathrm{CHF}$ & & & & 0.001 \\
\hline No & 3472 & $1.62(1.33,1.95)$ & $<0.001$ & \\
\hline Yes & 1529 & $1.86(1.38,2.50)$ & $<0.001$ & \\
\hline CLD & & & & $<0.001$ \\
\hline No & 4211 & $2.28(1.88,2.77)$ & $<0.001$ & \\
\hline Yes & 790 & $1.19(0.78,1.79)$ & 0.421 & \\
\hline CKD & & & & 0.022 \\
\hline No & 4224 & $1.76(1.48,2.09)$ & $<0.001$ & \\
\hline Yes & 777 & $1.35(0.92,1.99)$ & 0.128 & \\
\hline COPD & & & & 0.502 \\
\hline No & 4941 & $1.73(1.47,2.02)$ & $<0.001$ & \\
\hline Yes & 60 & $0.86(0.17,4.26)$ & 0.852 & \\
\hline ARDS & & & & $<0.001$ \\
\hline No & 3215 & $2.09(1.63,2.68)$ & $<0.001$ & \\
\hline Yes & 1786 & $0.98(0.79,1.19)$ & 0.751 & \\
\hline Pneumonia & & & & $<0.001$ \\
\hline No & 3486 & $1.40(1.15,1.71)$ & 0.001 & \\
\hline Yes & 1515 & $1.49(1.14,1.95)$ & 0.003 & \\
\hline Stroke & & & & 0.002 \\
\hline No & 4789 & $1.74(1.48,2.05)$ & $<0.001$ & \\
\hline Yes & 212 & $1.09(0.53,2.23)$ & 0.823 & \\
\hline Cancer & & & & $<0.001$ \\
\hline No & 4024 & $1.55(1.29,1.86)$ & $<0.001$ & \\
\hline Yes & 977 & $1.86(1.30,2.65)$ & 0.001 & \\
\hline Diabetes & & & & 0.671 \\
\hline No & 3664 & $1.61(1.34,1.93)$ & $<0.001$ & \\
\hline Yes & 1337 & $2.02(1.45,2.80)$ & $<0.001$ & \\
\hline RRT & & & & $<0.001$ \\
\hline No & 4704 & $1.02(0.84,1.23)$ & 0.876 & \\
\hline Yes & 297 & $1.73(1.23,2.44)$ & 0.002 & \\
\hline
\end{tabular}

Table 3 (continued)

\begin{tabular}{|c|c|c|c|c|}
\hline Characteristic & $N$ & HR (95\%CI) & $P$ value & $P$ for interaction \\
\hline \multicolumn{4}{|l|}{ AKI stage } & $<0.001$ \\
\hline Stage 1 & 485 & $0.67(0.43,1.03)$ & 0.065 & \\
\hline Stage 2 & 1250 & $1.20(0.92,1.56)$ & 0.184 & \\
\hline Stage 3 & 3266 & $2.10(1.69,2.63)$ & $<0.001$ & \\
\hline \multicolumn{4}{|l|}{ WBC, $10^{9} / \mathrm{L}$} & 0.032 \\
\hline$<11.2$ & 2479 & $1.06(0.85,1.33)$ & 0.600 & \\
\hline$\geq 11.2$ & 2522 & $1.28(1.01,1.61)$ & 0.039 & \\
\hline \multicolumn{4}{|c|}{ Creatine, $\mathrm{mEq} / \mathrm{L}$} & $<0.001$ \\
\hline$<1.1$ & 2173 & $1.17(0.89,1.54)$ & 0.273 & \\
\hline$\geq 1.1$ & 2828 & $1.11(0.91,1.34)$ & 0.306 & \\
\hline \multicolumn{4}{|l|}{ BUN, mg/dL } & $<0.001$ \\
\hline$<23$ & 2382 & $1.22(0.90,1.65)$ & 0.207 & \\
\hline$\geq 23$ & 2619 & $0.95(0.79,1.14)$ & 0.576 & \\
\hline \multicolumn{4}{|c|}{ Anion gap, mmol/L } & $<0.001$ \\
\hline$<15$ & 2310 & $1.32(1.00,1.74)$ & 0.052 & \\
\hline$\geq 15$ & 2679 & $1.07(0.89,1.30)$ & 0.470 & \\
\hline \multicolumn{4}{|c|}{ Bicarbonate, mg/dL } & $<0.001$ \\
\hline$<22$ & 2192 & $0.95(0.78,1.16)$ & 0.604 & \\
\hline$\geq 22$ & 2809 & $1.48(1.15,1.92)$ & 0.003 & \\
\hline \multicolumn{4}{|c|}{ Bilirubin, mg/dL } & $<0.001$ \\
\hline$<0.8$ & 2089 & $2.53(1.74,3.66)$ & $<0.001$ & \\
\hline$\geq 0.8$ & 2567 & $1.01(0.83,1.22)$ & 0.915 & \\
\hline \multicolumn{4}{|l|}{ Glucose, mg/dL } & 0.301 \\
\hline$<133$ & 2447 & $1.16(0.92,1.45)$ & 0.206 & \\
\hline$\geq 133$ & 2538 & $1.18(0.95,1.48)$ & 0.137 & \\
\hline \multicolumn{4}{|l|}{ Hematocrit, \% } & 0.574 \\
\hline$<30.8$ & 2496 & $1.08(0.88,1.35)$ & 0.456 & \\
\hline$\geq 30.8$ & 2505 & $1.29(1.02,1.64)$ & 0.035 & \\
\hline \multicolumn{4}{|c|}{ Sodium, mmol/L } & 0.006 \\
\hline$<139$ & 2381 & $1.00(0.80,1.25)$ & 0.977 & \\
\hline$\geq 139$ & 2618 & $1.38(1.11,1.73)$ & 0.005 & \\
\hline \multicolumn{4}{|c|}{ Potassium, mmol/L } & $<0.001$ \\
\hline$<4.1$ & 2225 & $1.05(0.82,1.34)$ & 0.714 & \\
\hline$\geq 4.1$ & 2767 & $1.30(1.06,1.60)$ & 0.011 & \\
\hline \multicolumn{4}{|l|}{ Platelet, $10^{9} / \mathrm{L}$} & $<0.001$ \\
\hline$<168$ & 2487 & $1.20(0.98,1.47)$ & 0.071 & \\
\hline$\geq 168$ & 2514 & $1.61(1.19,2.18)$ & 0.002 & \\
\hline \multicolumn{4}{|c|}{ Chloride, mmol/L } & $<0.001$ \\
\hline$<105$ & 2214 & $1.05(0.84,1.32)$ & 0.658 & \\
\hline$\geq 105$ & 2787 & $1.28(1.02,1.60)$ & 0.032 & \\
\hline \multicolumn{4}{|c|}{ Hemoglobin, g/dL } & 0.008 \\
\hline$<10.4$ & 2480 & $1.12(0.91,1.38)$ & 0.276 & \\
\hline$\geq 10.4$ & 2521 & $1.26(0.99,1.61)$ & 0.061 & \\
\hline \multicolumn{4}{|l|}{ PT, seconds } & $<0.001$ \\
\hline$<15.5$ & 2451 & $1.57(1.15,2.13)$ & 0.005 & \\
\hline$\geq 15.5$ & 2547 & $1.20(0.99,1.45)$ & 0.067 & \\
\hline \multicolumn{4}{|l|}{ APTT, seconds } & $<0.001$ \\
\hline$<35$ & 2488 & $1.44(1.06,1.96)$ & 0.021 & \\
\hline$\geq 35$ & 2509 & $1.27(1.05,1.54)$ & 0.016 & \\
\hline
\end{tabular}


Table 3 (continued)

\begin{tabular}{lllll}
\hline Characteristic & $N$ & HR $(95 \% \mathrm{CI})$ & $P$ value & $P$ for interaction \\
\hline SOFA score & & & & $<0.001$ \\
& & & & \\
$<5$ & 1542 & $2.90(1.85,4.86)$ & $<0.001$ & \\
$\geq 5$ & 3459 & $1.58(1.33,1.87)$ & $<0.001$ & \\
SAPSII score & & & & $<0.001$ \\
$\quad<39$ & 2020 & $1.61(1.10,2.36)$ & 0.014 & \\
$\geq 39$ & 2981 & $1.45(1.22,1.73)$ & $<0.001$ & \\
\hline
\end{tabular}

$A R D S$ acute respiratory distress syndrome, $C O P D$ chronic obstructive pulmonary disease, $B U N$ blood urea nitrogen, $W B C$ white blood cell, $P T$ prothrombin time, $A P T T$ activated partial thromboplastin time, SOFA sequential organ failure assessment, SAPSII simplified acute physiology score II

can be utilized as a readily available indicator for assessing microinflammation [10, 12], and recent studies have associated it with inflammation-based disease, which is associated with increased mortality in critically ill patients [22]. Similarly, the present study showed that FAR was an independent predictor in critically patients with AKI. The following reason might be accounted for in our findings. Many immune cells involved in acute and chronic inflammation generated and released a wide variety of inflammatory factors, such as transforming growth factor- $\beta$ (TGF- $\beta$ ), vascular endothelial growth factor (VEGF), and platelet-derived growth factor
(PDGF) [23] [24]. However, the precise mechanism needs further investigation. Elevated fibrinogen level resulted in activation of proinflammatory cascades, which lead to the release of inflammatory cytokines and thereby contribute to the occurrence and development of inflammation diseases [25, 26]. Moreover, inhibition of fibrinogen resulted in reduced inflammation and an attenuated disease course [27]. Previous studies have reported that plasma fibrinogen level in AKI patients was higher than the normal range and an increased blood viscosity due to elevated fibrinogen level was independently associated with increased risk of cardiovascular events [28-30]. In addition, higher fibrinogen was associated with the presence of AKI in abdominal aortic aneurysm repair patients [29], and predicted the development of AKI in contrast-induced nephropathy [31].

Serum albumin is commonly used to evaluate nutritional status of patients. Recent studies found hypoalbuminemia negatively correlated with patient prognosis was more greatly attributed to systemic inflammation than malnutrition in various disease [32, 33]. Moreover, a nonlinear relationship between albumin and mortality was also observed [34]. A sufficient amount of albumin is likely to protect kidneys from toxic substances and maintain colloid pressure to guarantee perfusion [35], all of which are risk factors for the development of AKI. As reported previously, AKI was associated with local and systemic inflammation [36], as markers of inflammation, fibrinogen and albumin have

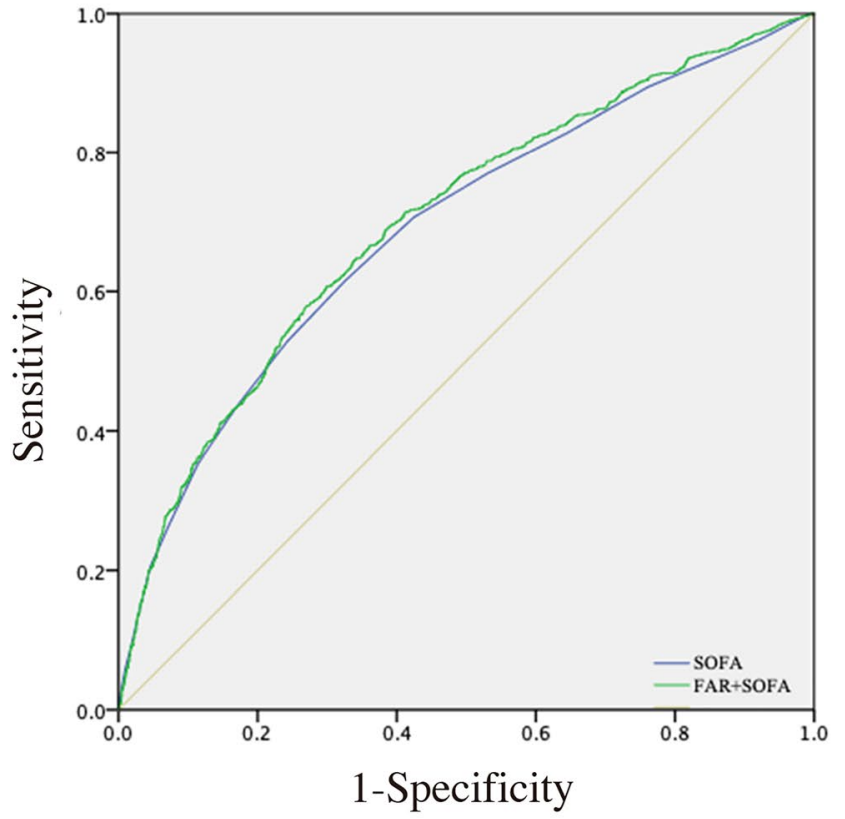

a

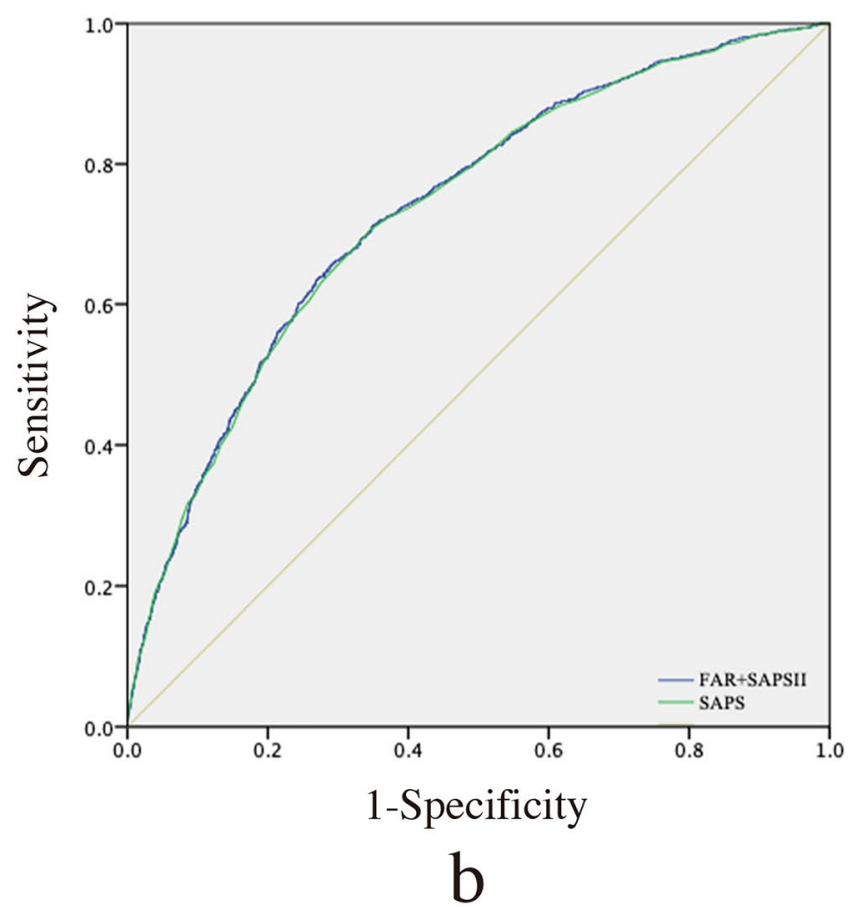

Fig. 2 ROC curves for the prediction of in-hospital mortality. a The ability of SOFA scores and FAR plus SOFA scores to predict in-hospital mortality. b The ability of SAPSII scores and FAR plus SAPSII scores to predict in-hospital mortality 
been investigated as significant predictors in AKI patients $[37,38]$. All of these results led us to conclude the predictive value of FAR is enhanced in the AKI population. Next, we further investigated the association between FAR and mortality using a generalized additive model and discovered that the relationship between FAR and in-hospital mortality was nonlinear, exhibiting approximate U-shaped curves. Combined with the basic characteristics results, where patients with roughly normal FAR level (Q2 group) had the lowest mortality rate, suggesting that the FAR level was associated with in-hospital mortality in a U-shaped relationship, indicating that there might be a normal value range of FAR level in the middle of the entire distribution rather than on either side. Extremely low FAR level should also lead to poor prognosis among critically ill patients with AKI. Indeed, a retrospective study in CKD patients demonstrated that lower fibrinogen can lead to an increased risk of bleeding and correlate with increased CV event mortality [39]. However, we did not find that lower FAR was associated with in-hospital mortality in AKI patients. This may be because bleeding is multifactorial and partially due to uremic disturbance of platelet adhesion, anemia, fibrinolysis, and coagulation [40]. The interactive influence among multiple factors could conceal the effect of FAR level alone on the prognosis of critically ill patients with AKI.

The subgroup analysis of in-hospital mortality revealed a positive association of an increased FAR with mortality in AKI patients with CAD. Prior studies have illustrated that cardiovascular disease may affect the outcome of AKI [41]. Interestingly, we found that AKI patients with malignancy were associated with higher mortality. Cancer patients requiring admission to the ICU are typically older, more likely required mechanical ventilation, more susceptible to severe sepsis and a higher incidence of nephrotoxicity induced by targeted therapy, all of which are common risk factors associated with increased ICU readmission or mortality [42, 43]. It is well known that the mortality in cancer patients with AKI was higher than that without AKI [44]. However, a previous study demonstrated that cancer patients with AKI correlated with reduced mortality, indicating a complex and even paradoxical relationship of AKI and clinical risk in cancer patients [45]. Furthermore, we found the risk of AKI was high following pneumonia, this might be related to an increased immune response of pneumonia [46, 47]. Clearly, further research into mechanisms underlying the interaction between potential factors and poor outcomes is required.

There are some unavoidable limitations in our study. First, this was a retrospective study based on a single-center database, and selection bias was inevitable. Second, we only measured FAR upon admission to the ICU, whether infusion of fibrinogen or albumin during ICU stay may affect outcome, especially in patients with high baseline levels should be further verified. Third, we did not adjust all factors related to mortality owing to lack of related data. Finally, we only investigate in-hospital mortality which may affect assessment of prognosis, the follow-up length of mortality should be considered in the future analysis.

\section{Conclusion}

We found a U-shaped relationship between the FAR and mortality and a higher level of FAR was associated with increased risk of in-hospital mortality in critically ill patients with AKI. However, our findings still need to be confirmed by large prospective studies with long follow-up.

Author contributions CL developed the protocol; YC, TZ and XY collected, analyzed and interpreted data; WX drafted the manuscript; YZ made the figures and $\mathrm{HH}$ supervised the project. All authors read and approved the final manuscript.

Funding The research was supported by a grant from Scientific Research Project of Wuxi Health Committee (Q201754). The funding body had no role in the in the design of the study, collection, analysis, interpretation of the data and the writing of the manuscript.

Data availability The clinical data used to support the findings of this study were supplied by Monitoring in Intensive Care Database III version 1.4 (MIMIC-III v.1.4). Although the database is publicly and freely available, researchers must complete the National Institutes of Health's web-based course known as Protecting Human Research Participants to apply for permission to access the database. The datasets used and/or analyzed during the current study are available from the corresponding author on reasonable request.

\section{Declarations}

Conflict of interest The authors declare that they have no competing interests.

Ethical approval The MIMIC-III database has received ethical approval from the institutional review boards (IRBs) at Beth Israel Deaconess Medical Center and Massachusetts Institute of Technology. Because the database does not contain protected health information, a waiver of the requirement for informed consent was included in the IRB approval.

Consent for publication Not applicable.

Open Access This article is licensed under a Creative Commons Attribution 4.0 International License, which permits use, sharing, adaptation, distribution and reproduction in any medium or format, as long as you give appropriate credit to the original author(s) and the source, provide a link to the Creative Commons licence, and indicate if changes were made. The images or other third party material in this article are included in the article's Creative Commons licence, unless indicated otherwise in a credit line to the material. If material is not included in the article's Creative Commons licence and your intended use is not permitted by statutory regulation or exceeds the permitted use, you will 
need to obtain permission directly from the copyright holder. To view a copy of this licence, visit http://creativecommons.org/licenses/by/4.0/.

\section{References}

1. Wang HE, Muntner P, Chertow GM, Warnock DG (2012) Acute kidney injury and mortality in hospitalized patients. Am J Nephrol 35(4):349-355

2. Chawla LS, Amdur RL, Shaw AD, Faselis C, Palant CE, Kimmel PL (2014) Association between AKI and long-term renal and cardiovascular outcomes in United States veterans. Clin J Am Soc Nephrol 9(3):448-456

3. Puher SL, Bucaloiu ID, Perkins RM (2011) Early nephrologic consultation after acute kidney injury. Am J Kidney Dis 58(1):154-155 (Author reply 155)

4. Zuk A, Bonventre JV (2016) Acute kidney injury. Annu Rev Med 67:293-307

5. Kinsey GR, Li L, Okusa MD (2008) Inflammation in acute kidney injury. Nephron Exp Nephrol 109(4):e102-107

6. Jang HR, Rabb H (2015) Immune cells in experimental acute kidney injury. Nat Rev Nephrol 11(2):88-101

7. Gameiro J, Fonseca JA, Dias JM, Milho J, Rosa R, Jorge S, Lopes JA (2018) Neutrophil, lymphocyte and platelet ratio as a predictor of postoperative acute kidney injury in major abdominal surgery. BMC Nephrol 19(1):320

8. Tanase DM, Gosav EM, Radu S, Costea CF, Ciocoiu M, Carauleanu A, Lacatusu CM, Maranduca MA, Floria M, Rezus C (2019) The predictive role of the biomarker kidney molecule-1 (KIM-1) in acute kidney injury (AKI) cisplatin-induced nephrotoxicity. Int J Mol Sci. https://doi.org/10.3390/ijms20205238

9. Malhotra R, Siew ED (2017) Biomarkers for the early detection and prognosis of acute kidney injury. Clin J Am Soc Nephrol 12(1):149-173

10. Zhang J, Ding Y, Wang W, Lu Y, Wang H, Wang H, Teng L (2020) Combining the fibrinogen/albumin ratio and systemic inflammation response index predicts survival in resectable gastric cancer. Gastroenterol Res Pract 2020:3207345

11. Zheng Y, Wu C, Yan H, Chen S (2020) Prognostic value of combined preoperative fibrinogen-albumin ratio and platelet-lymphocyte ratio score in patients with breast cancer: a prognostic nomogram study. Clin Chim Acta 506:110-121

12. Xu Q, Yan Y, Gu S, Mao K, Zhang J, Huang P, Zhou Z, Chen Z, Zheng S, Liang J et al (2018) A novel inflammation-based prognostic score: the fibrinogen/albumin ratio predicts prognoses of patients after curative resection for hepatocellular carcinoma. J Immunol Res 2018:4925498

13. Xiao L, Jia Y, Wang X, Huang H (2019) The impact of preoperative fibrinogen-albumin ratio on mortality in patients with acute ST-segment elevation myocardial infarction undergoing primary percutaneous coronary intervention. Clin Chim Acta 493:8-13

14. Ertas F, Avci E, Kiris T (2019) The ratio of fibrinogen to albumin as a predictor of contrast-induced nephropathy after carotid angiography. Angiology 70(5):458-464

15. Wang C, Li G, Liang X, Qin C, Luo Q, Song R, Chen W (2020) Predictive value of fibrinogen-to-albumin ratio for post-contrast acute kidney injury in patients undergoing elective percutaneous coronary intervention. Med Sci Monit. https://doi.org/10.12659/ MSM.924498

16. Johnson AE, Pollard TJ, Shen L, Lehman LW, Feng M, Ghassemi M, Moody B, Szolovits P, Celi LA, Mark RG (2016) MIMIC-III, a freely accessible critical care database. Sci Data. https://doi.org/ 10.1038/sdata.2016.35
17. Allard J, Cotin S, Faure F, Bensoussan PJ, Poyer F, Duriez C, Delingette H, Grisoni L (2007) SOFA - an open source framework for medical simulation. Stud Health Technol Inform 125:13-18

18. Le Gall JR, Lemeshow S, Saulnier F (1993) A new simplified acute physiology score (SAPS II) based on a European/North American multicenter study. JAMA 270(24):2957-2963

19. Zou Y, Zhu Z, Zhou J, Wu X, Li H, Ning X, Shi Y, Niu H (2020) Fibrinogen/Albumin ratio: a more powerful prognostic index for patients with end-stage renal disease. Eur J Clin Invest. https:// doi.org/10.1111/eci.13266

20. Liu J, Gan Y, Song H, Zhu K, Zhang Q (2020) The predictive value of the preoperative fibrinogen-albumin ratio on the postoperative prognosis of renal cell carcinoma. Transl Androl Urol 9(3):1053-1061

21. Luyendyk JP, Schoenecker JG, Flick MJ (2019) The multifaceted role of fibrinogen in tissue injury and inflammation. Blood 133(6):511-520

22. Winkelman C (2007) Inactivity and inflammation in the critically ill patient. Crit Care Clin 23(1):21-34

23. Martino MM, Briquez PS, Ranga A, Lutolf MP, Hubbell JA (2013) Heparin-binding domain of fibrin(ogen) binds growth factors and promotes tissue repair when incorporated within a synthetic matrix. Proc Natl Acad Sci U S A 110(12):4563-4568

24. Schultz GS, Chin GA, Moldawer L, Diegelmann RF (2011) Principles of wound healing. In: Fitridge R, Thompson M (eds) Mechanisms of vascular disease: a reference book for vascular specialists. Adelaide

25. Flick MJ, LaJeunesse CM, Talmage KE, Witte DP, Palumbo JS, Pinkerton MD, Thornton S, Degen JL (2007) Fibrin(ogen) exacerbates inflammatory joint disease through a mechanism linked to the integrin alphaMbeta2 binding motif. J Clin Invest 117(11):3224-3235

26. Gobel K, Eichler S, Wiendl H, Chavakis T, Kleinschnitz C, Meuth SG (2018) The coagulation factors fibrinogen, thrombin, and factor XII in inflammatory disorders-a systematic review. Front Immunol 9:1731

27. Adams RA, Bauer J, Flick MJ, Sikorski SL, Nuriel T, Lassmann H, Degen JL, Akassoglou K (2007) The fibrin-derived gamma377395 peptide inhibits microglia activation and suppresses relapsing paralysis in central nervous system autoimmune disease. J Exp Med 204(3):571-582

28. Sorensen-Zender I, Rong S, Susnik N, Lange J, Gueler F, Degen JL, Melk A, Haller H, Schmitt R (2013) Role of fibrinogen in acute ischemic kidney injury. Am J Physiol Renal Physiol 305(5):F777-785

29. Hoffmann D, Bijol V, Krishnamoorthy A, Gonzalez VR, Frendl G, Zhang Q, Goering PL, Brown RP, Waikar SS, Vaidya VS (2012) Fibrinogen excretion in the urine and immunoreactivity in the kidney serves as a translational biomarker for acute kidney injury. Am J Pathol 181(3):818-828

30. Ozcan Cetin EH, Konte HC, Temizhan A (2019) Blood viscosity should not be overlooked when evaluating the fibrinogen to albumin ratio. Angiology 70(5):465-466

31. Celik IE, Kurtul A, Duran M, Yarlioglues M, Elcik D, Kilic A, Koseoglu C, Oksuz F, Murat SN (2016) Elevated serum fibrinogen levels and risk of contrast-induced acute kidney injury in patients undergoing a percutaneous coronary intervention for the treatment of acute coronary syndrome. Coron Artery Dis 27(1):13-18

32. Kaysen GA (2003) Serum albumin concentration in dialysis patients: why does it remain resistant to therapy? Kidney Int Suppl 87:S92-98

33. Soeters PB, Wolfe RR, Shenkin A (2019) Hypoalbuminemia: pathogenesis and clinical significance. JPEN J Parenter Enteral Nutr 43(2):181-193 
34. Weiner DE, Tighiouart H, Elsayed EF, Griffith JL, Salem DN, Levey AS, Sarnak MJ (2008) The relationship between nontraditional risk factors and outcomes in individuals with stage 3 to 4 CKD. Am J Kidney Dis 51(2):212-223

35. Contreras AM, Ramirez M, Cueva L, Alvarez S, de Loza R, Gamba G (1994) Low serum albumin and the increased risk of amikacin nephrotoxicity. Rev Invest Clin 46(1):37-43

36. Doi K, Rabb H (2016) Impact of acute kidney injury on distant organ function: recent findings and potential therapeutic targets. Kidney Int 89(3):555-564

37. Yang JJ, Lei WH, Hu P, Wu BB, Chen JX, Ni YM, Lai EY, Han F, Chen JH, Yang Y (2020) Preoperative serum fibrinogen is associated with acute kidney injury after cardiac valve replacement surgery. Sci Rep 10(1):6403

38. Thongprayoon C, Cheungpasitporn W, Mao MA, Sakhuja A, Kashani K (2018) U-shape association of serum albumin level and acute kidney injury risk in hospitalized patients. PLoS ONE. https://doi.org/10.1371/journal.pone.0199153

39. Tanhehco YC, Berns JS (2012) Red blood cell transfusion risks in patients with end-stage renal disease. Semin Dial 25(5):539-544

40. Mohapatra A, Valson AT, Gopal B, Singh S, Nair SC, Viswabandya A, Varughese S, Tamilarasi V, John GT (2018) Hemostatic abnormalities in severe renal failure: do they bark or bite? Indian J Nephrol 28(2):135-142

41. Cruz DN, Bagshaw SM, Maisel A, Lewington A, Thadhani R, Chakravarthi R, Murray PT, Mehta RL, Chawla LS (2013) Use of biomarkers to assess prognosis and guide management of patients with acute kidney injury. Contrib Nephrol 182:45-64
42. AbuSara AK, Nazer LH, Hawari FI (2019) ICU readmission of patients with cancer: Incidence, risk factors and mortality. J Crit Care 51:84-87

43. Jeong BH, Na SJ, Lee DS, Chung CR, Suh GY, Jeon K (2019) Readmission and hospital mortality after ICU discharge of critically ill cancer patients. PLoS ONE. https://doi.org/10.1371/journ al.pone. 0211240

44. Lameire N, Vanholder R, Van Biesen W, Benoit D (2016) Acute kidney injury in critically ill cancer patients: an update. Crit Care 20(1):209

45. Fan LL, Wang YJ, Nan CJ, Chen YH, Su HX (2019) Neutrophillymphocyte ratio is associated with all-cause mortality among critically ill patients with acute kidney injury. Clin Chim Acta 490:207-213

46. Lin TY, Chen YG, Lin CL, Kao CH (2016) Increased risk of acute kidney injury following pneumococcal pneumonia: a nationwide cohort study. PLoS ONE. https://doi.org/10.1371/journal.pone. 0158501

47. Murugan R, Karajala-Subramanyam V, Lee M, Yende S, Kong L, Carter M, Angus DC, Kellum JA (2010) Genetic, inflammatory markers of sepsis I: acute kidney injury in non-severe pneumonia is associated with an increased immune response and lower survival. Kidney Int 77(6):527-535

Publisher's Note Springer Nature remains neutral with regard to jurisdictional claims in published maps and institutional affiliations. 